\title{
Optimal electroacoustic coating modes investigation for production of nanostructured materials
}

\author{
Wisam Al-Tibbi ${ }^{1, *}$ \\ ${ }^{1}$ Don State Technical University, Gagarin sq. 1, 344003 Rostov-on-Don, Russia
}

\begin{abstract}
Described the research results of hardening coatings coating modes influence on the microstructure of the surface layer of machine parts. Electroacoustic coating was used as a coating method. X-ray structural analysis and electron microscopy were used to investigate the microstructure of the coatings. The results obtained can be used to determine the optimal technological modes of coating.
\end{abstract}

\section{Introduction}

The problem of ultrafine-grained materials production intended for various fields of technology is the subject of constant discussion by the scientific community [1-7]. Ongoing research in this area is a consequence of the discovery of regularities that lead to the emergence of new material properties (including metals and alloys based on them) as the geometric parameters of their crystal lattice decrease. New properties of such materials include high resistance to wear and increased strength characteristics, which are important in the operation of machine parts and forming tools.

There are various types of such materials [1-7]. This article is devoted to a potentially new for nanostructured coatings production method by electroacoustic coating. Such coatings allow significantly (5-8 times) to increase the continuous operation time of parts and mechanisms, as well as forming tools [8-9].

\section{Materials and Methods}

To produce protective coatings, the method of electroacoustic coating (ELAC) was used. The physical foundations of the ELAC method were presented in [8-9]. To determine the content of the amorphous phase in the sputtered material, we used the general principles of evaluating the production of amorphous materials discussed in the works of D. Ullman and G. Davis. [10]. The solution of the two-dimensional thermal conductivity problem with boundary conditions of the 2 nd kind was performed by considering the problem describing the change in the phase state of the substance, in which the position of the phase boundaries changes with time (Stefan problem) [11-12].

\footnotetext{
*Corresponding author: nb1979@mail.ru
} 
One of the following materials was used as anode material - copper (Cu-ETP), tungsten $(\mathrm{B} 7 \mathrm{~K})$ and technical iron $\left(\mathrm{Fe}_{3}\right)$. The calculations were made with changing the value of heat flux power (by changing the value of the spark gap voltage, the range of operating voltages varied from 9 to $42 \mathrm{~V}$ ).

$\mathrm{X}$-ray studies were produced on an X-ray diffractometer with characteristic radiation of the iron electrode on a multifunctional X-ray diffractometer DRON-8. Parameters of the coating process used in its application: voltage in the interelectrode gap from 9 to $42 \mathrm{~V}$; amplitude of ultrasonic vibrations of the end of the waveguide from 4 to 16 microns. The percentage of amorphous phase was estimated from the ratio of peak intensities of the sample and the reference (without considering the texture component). The influence of the parameters of the reflection profiles on the size of crystallites was estimated by the halfwidth of the peaks (Scherrer and Williamson-Hall methods) [13-15].

As a visual demonstration, as well as to confirm the X-ray data, the surface layer of the coatings was examined using scanning electron microscopy on a Philips SEM microscope. The materials used for coating were Cu-ETP copper, HG30 carbide and C10 steel. All materials were deposited on C10 steel samples. Additionally, the microstructure of the original samples was studied. The mode of electroacoustic sputtering was chosen in agreement with the modes used in mathematical modeling and X-ray analysis.

\subsection{Mathematical modeling of crystallization processes}

The formation of a fine-dispersed crystalline structure in the surface layer of the studied materials is possible under several conditions, which can be estimated from the data of theoretical calculations of the cooling parameters of the melt in the melt bath, as well as the movement of the crystallization front. The critical condition in this case is the appearance of an amorphous component in the coating. In our case, it is necessary to consider preconditions that allow reducing the percentage of the amorphous phase and increasing the content of crystallites with nanostructured dimensions.

The energy of an electric spark is used as the thermal source in these calculations, although ultrasonic vibrations should also contribute to the crystallization processes, although much less. The voltage at the electrode was varied in the same range as above (from 9 to $42 \mathrm{~V}$ ).

Table 1. Calculations results.

\begin{tabular}{|c|c|c|c|c|c|c|c|c|c|c|}
\hline $\begin{array}{c}\text { Mater } \\
\text { ial }\end{array}$ & $\begin{array}{l}\boldsymbol{U}, \\
\mathbf{V}\end{array}$ & $\begin{array}{c}W_{\text {cl.max }}{ }^{*} \\
\mathbf{1 0}^{10}, \\
\mathbf{K} / \mathrm{s}\end{array}$ & $\begin{array}{c}T_{\max }, \\
{ }^{\circ} \mathrm{C}\end{array}$ & $\begin{array}{c}W_{\text {cl.krt }} \\
\mathbf{1 0}^{10} \\
\mathbf{K} / \mathbf{s}\end{array}$ & $\begin{array}{l}T_{\mathrm{B}}, \\
{ }^{\circ} \mathrm{C}\end{array}$ & $\begin{array}{c}t_{\mathrm{B}} \cdot \\
10^{-8} \\
\mathrm{~S}\end{array}$ & $\begin{array}{c}t_{\mathrm{cl}}{ }^{-7} \\
10^{-7} \\
\mathbf{S}\end{array}$ & $\begin{array}{c}h, \\
\mu \mathrm{m}\end{array}$ & $\begin{array}{c}r_{\text {max. }}, \\
\text { nm }\end{array}$ & $\begin{array}{l}\eta_{\mathrm{a}}, \\
\%\end{array}$ \\
\hline \multirow[t]{2}{*}{$\mathrm{Fe}$} & 30 & 4.1 & 6821 & \multirow[b]{2}{*}{3.136} & \multirow[b]{2}{*}{1100} & \multirow[b]{2}{*}{1.4} & 2.1 & 2.7 & 60 & 50 \\
\hline & 20 & 1 & 4298 & & & & 1 & 1.75 & 60 & 0 \\
\hline \multirow[t]{2}{*}{ W } & 30 & 2.1 & 4428 & \multirow[b]{2}{*}{44.65} & \multirow[b]{2}{*}{2230} & \multirow[b]{2}{*}{0.39} & 0.2 & 0.4 & 5000 & 0 \\
\hline & 40 & 15 & 6916 & & & & 2.1 & 1.1 & 800 & 0 \\
\hline \multirow[t]{2}{*}{$\mathrm{Cu}$} & 20 & 3.1 & 5695 & \multirow[b]{2}{*}{0.789} & \multirow[b]{2}{*}{880} & \multirow[b]{2}{*}{11} & 0.15 & 3.5 & 18 & 70 \\
\hline & 12 & 0.58 & 1514 & & & & 0.04 & 0.5 & 18 & 0 \\
\hline
\end{tabular}

In Table 1: $U$ - voltage on the electrode; $\mathrm{W}_{\text {cl.max. }}$ - maximum speed of cooling; $\mathrm{T}_{\max }$ maximum temperature of the melt; $T_{f}$ - temperature at the cooling front; $t_{f}$ - time to the beginning of crystallization; $\mathrm{W}_{\text {cl.krt. }}$ - critical rate of melt cooling; $\mathrm{t}_{\mathrm{cl}}$ - time of melt complete solidification; $\mathrm{r}_{\max }$ - maximum radius of crystallites; $\mathrm{h}$ - penetration depth; $\eta_{\mathrm{a}}$ - volume content of amorphous phase.

According to calculations it is found: 1) the average calculated grain size of crystallites for different materials is in the range from 2 to $200 \mathrm{~nm}$. Thus finer grains are observed in layers of coverings situated closer to a substrate (cathode), because hardening processes 
propagate from a substrate; the calculated critical cooling rate necessary for melt amorphization for various materials is from $1 \cdot 10^{10}$ to $\left.4 \cdot 10^{11}(\mathrm{~K} / \mathrm{s}) ; 3\right)$ the calculated cooling rate of melt for various cooling conditions varies from $5 \cdot 10^{9}$ to $\left.1 \cdot 10^{11}(\mathrm{~K} / \mathrm{s}) 4\right)$ Depending on critical cooling rate required for melt amorphization and estimated cooling rate observed during solidification, the volume of crystal phase may be in the range from 10 to $100 \%$; ) obtaining nanostructure coatings when iron is used as cathode material is possible, but in this case one can get rid of amorphous phase completely only at low values of heat flow power (at U voltage $20 \mathrm{~V}$ ). According to theoretical calculations, the size of crystallites in this case ranges from 20 to $60 \mathrm{~nm} ; 5$ ) according to the data of theoretical calculations for tungsten, obtaining nanostructured and amorphous coatings is impossible, but there is a possibility of obtaining ultradispersed structures with a grain size of 0.2 - 10 microns; 6) for copper, obtaining nanostructures is theoretically possible, but the limit of complete elimination of the amorphous phase is close to the voltage of about $12 \mathrm{~V}$, the average size of crystallites is in the range $2-8 \mathrm{~nm} ; 7$ ) for these combinations of electrode materials in the same modes, simultaneously obtaining pure nanostructured coatings is not possible. Inclusions of amorphous phase in the surface layer will necessarily be present. Its percentage will vary over a wide range (from 0 to $90 \%$ ) depending on the electrode material and melting modes. For example, the voltage range for iron cathode (substrate) to produce completely nanostructured coatings ranges from 15 to $20 \mathrm{~V}$ and for copper from 10 to $15 \mathrm{~V}$. For a voltage of $15 \mathrm{~V}$, iron will solidify completely in the nanostructured phase, and copper with a percentage of the amorphous phase up to $70 \%$.

\subsection{Experimental study of the coatings structure obtained by the ELAC method}

\subsubsection{X-ray structural analysis}

According to the data of the X-ray analysis it was found that in case of sputtering by steel 10 (C10) electrode the grain size (CSR - coherent scattering regions) depending on ELAC modes varies in the range from 50 to $300 \mathrm{~nm}$. And with increasing voltage applied to the electrodes, the size of the CSR decreases, as well as with increasing amplitude. At sufficiently high voltage values (about $45 \mathrm{~V}$ ), an amorphous phase (halo on the X-ray image), the percentage of which reaches $60 \%$, can be observed in the coating material. In addition, a significant (about 1) shift of $\alpha$-Fe reflexes at large and small angles was observed, which is a consequence of changes in the lattice parameter within $1.15 \%$ and can serve in our opinion as a significant fact, indicating the refinement of grains (crystallites).

In case of sputtering with M0 copper electrode (Cu-ETP) two main phases $\alpha$-Fe and $\alpha$ $\mathrm{Cu}$ are present in the coating material. The broadening of diffraction peaks for both phases observed on X-ray diffraction patterns depends both on microdeformations (MCD) size and on the size of CSR. Depending on ELAC modes, the size of the CSR for $\alpha$-Fe varies from 50 to $200 \mathrm{~nm}$, and for $\alpha-\mathrm{Cu}$ from 20 to $200 \mathrm{~nm}$. And it also differs markedly from the calculated values. For $\alpha-\mathrm{Fe}$, the lattice parameter decreases with increasing voltage as well as with increasing amplitude. For $\alpha-\mathrm{Cu}$, the lattice parameter also decreases with increasing voltage, and increases with increasing amplitude.

In case of coating by the electrode from hard alloy HG30 two main phases $\alpha$-Fe, as well as the formed carbide of fast-cutting steel $\mathrm{Fe}_{3} \mathrm{~W}_{3} \mathrm{C}$ are present in the coating material. The broadening of the diffraction peaks for $\alpha$-Fe observed on the X-rays depends on both the MCD value and the size of the CSR. Depending on the ELAC modes, the size of the CSR for $\alpha$-Fe ranges from 100 to $230 \mathrm{~nm}$. For $\mathrm{Fe}_{3} \mathrm{~W}_{3} \mathrm{C}$, it was found that the error-adjusted broadening was caused by the MCD of the lattice, so it was not possible to determine the 
size of the CSR using the above technique. The shift of the peaks for $\mathrm{Fe}_{3} \mathrm{~W}_{3} \mathrm{C}$ carbide is practically absent (compared to the original substance).

\subsubsection{Scanning electron microscopy}

For all coated materials, it was found that the coating thickness at the used modes does not exceed $10-15 \mu \mathrm{m}$, which is clearly illustrated by the photo in Figure 1.

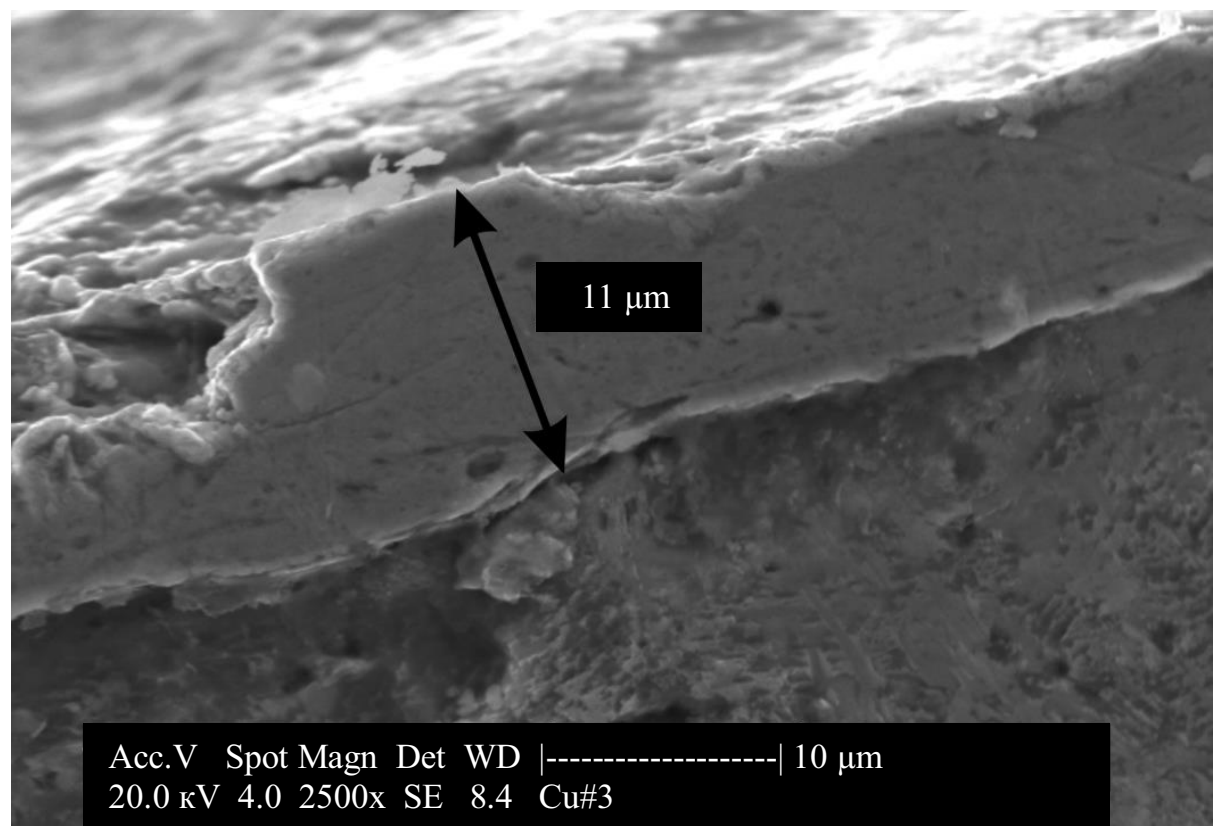

Fig. 1. Illustration of coating thickness obtained by the ELAC method (coating of copper $\mathrm{M} 0(\mathrm{Cu}-$ ETP), $\mathrm{U}=15 \mathrm{~V}, \mathrm{~A}=15 \mu \mathrm{m}$ ), magnification 2500 times

A photo of the microstructure of the original sample of steel 10 after etching in $4 \%$ nitric acid for 30 seconds is shown at Figure 2, and a photo of the microstructure of the sample coated with steel 10 after etching in $4 \%$ nitric acid for 30 seconds is shown at Figure 3.

As can be seen, the structure of the metal contains areas with significant heterogeneity (lighter areas) which can be interpreted as iron carbides not subjected to etching, present in any steel. It is obvious that the darker areas in the picture were formed because of iron etching by nitric acid.

The microstructure of the coating in Figure 3 contains areas of heterogeneity like at Figure 2, the size of which, however, has noticeably decreased. If in the substrate it was about $400 \mathrm{~nm}$, in the coating material its value was about $100 \mathrm{~nm}$. 


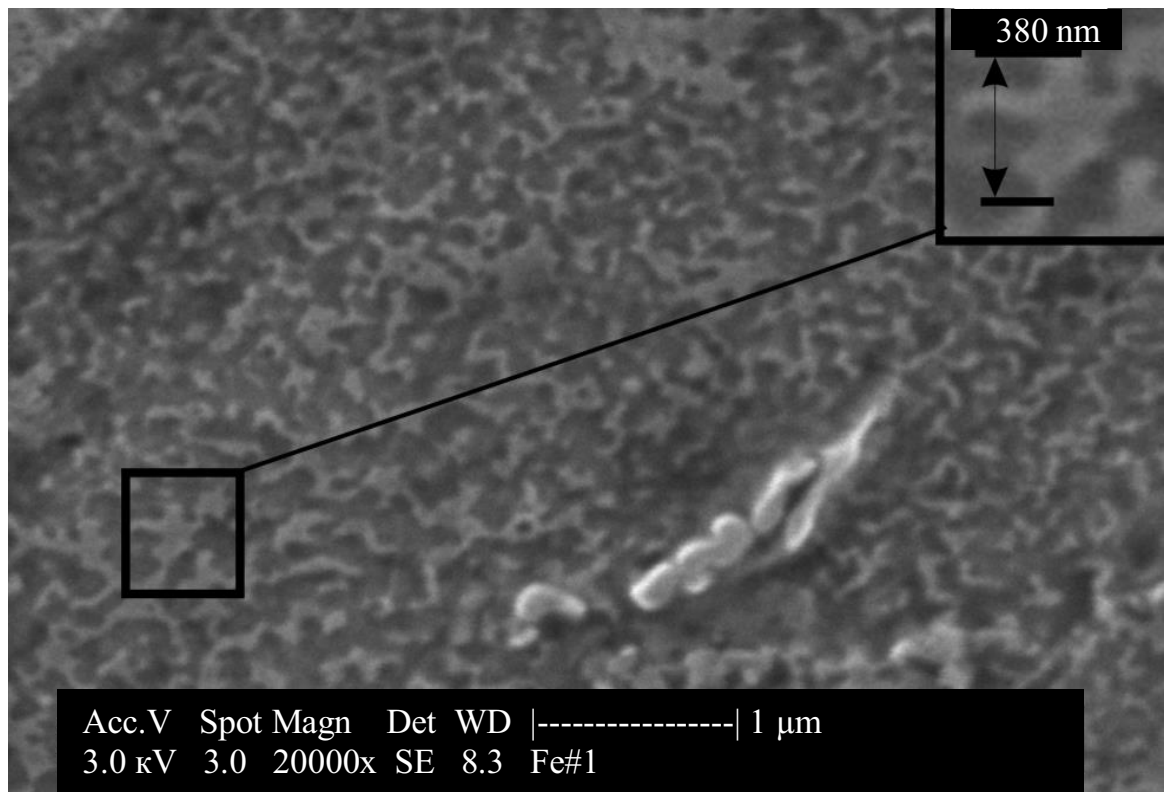

Fig. 2. Microstructure of steel $10(\mathrm{C} 10)$ layer, 20000x magnification

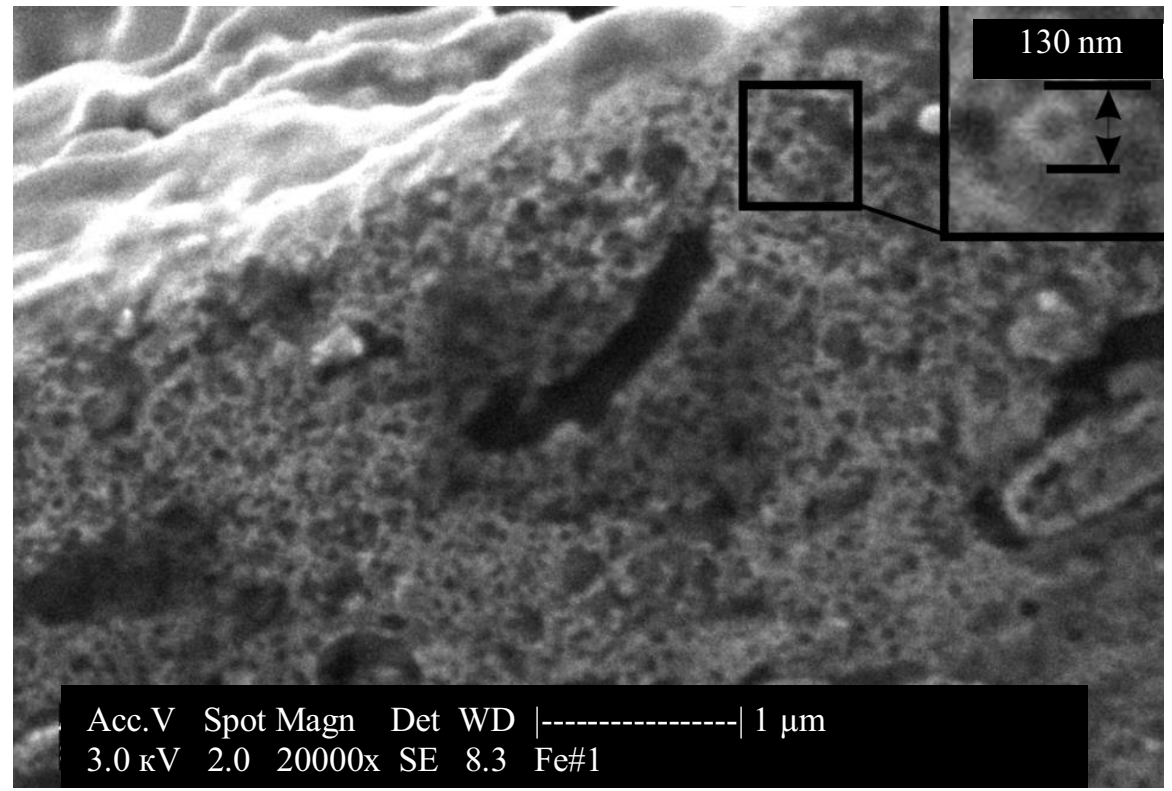

Fig. 3. Microstructure of steel 10 (C10) coating. $U=20 \mathrm{~V}, \mathrm{~A}=15 \mu \mathrm{m}, 20000 \mathrm{x}$ magnification

Figure 4 shows a photograph of the microstructure of the sample coated with copper after etching in $4 \%$ nitric acid for 30 seconds. 


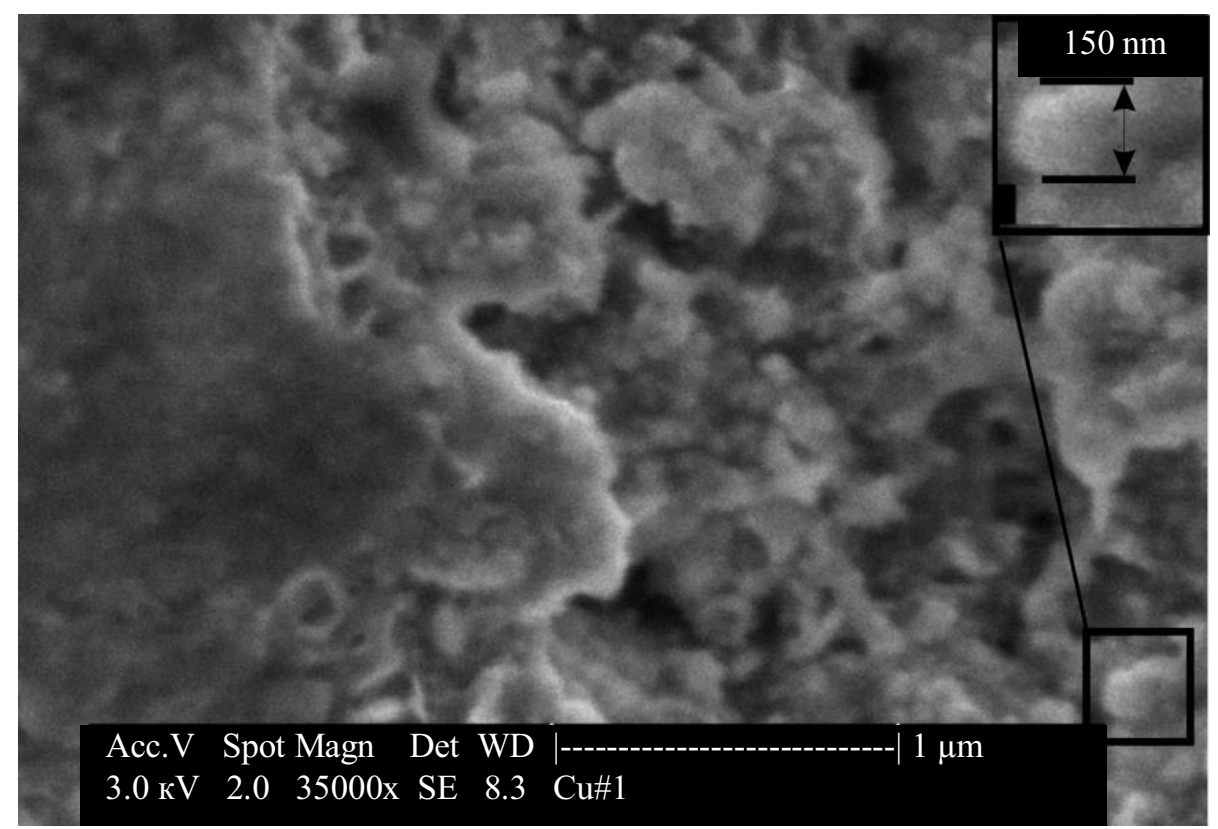

Fig. 4. Microstructure of $M 0$ copper coating (Cu-ETP), $U=15 \mathrm{~V}, \mathrm{~A}=15 \mu \mathrm{m}, 20000 \mathrm{x}$ magnification

As can be seen, the structure of the coating is very heterogeneous. It is easy to see traces of intense iron etching. The unetched areas are most likely copper areas, which are much less intensely etched in nitric acid. The size of these areas is again quite small and ranges from 100 to $150 \mathrm{~nm}$. Similar areas of heterogeneity are also observed in the case of coating with hard alloy BK8, but their size, as one would expect, is much larger (about $500 \mathrm{~nm}$ ). Figure 5 shows a photo of the microstructure of a sample coated with VK8 alloy after etching in $4 \%$ nitric acid for 30 seconds. The photo again shows traces of intense etching; if the etched areas consisted of iron, which is the most probable, the areas of heterogeneity formed in this case are the complex carbide $\mathrm{Fe}_{3} \mathrm{~W}_{3} \mathrm{C}$ mentioned above. 


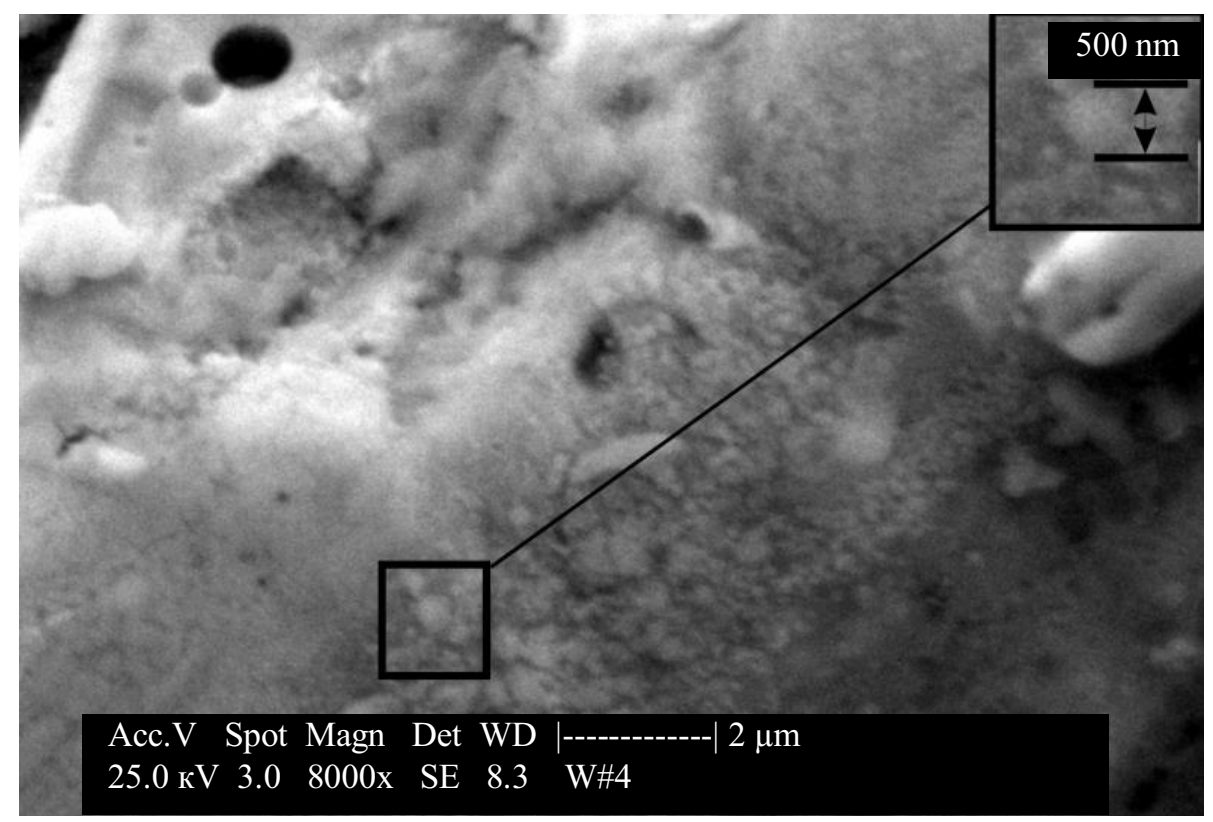

Fig. 5. Microstructure of coating coated with alloy HG30, $U=30 \mathrm{~V}, \mathrm{~A}=15 \mu \mathrm{m}$, magnification 8000 times

\section{Discussion}

It is known that at high rates of melt cooling (about $106 \mathrm{~K} / \mathrm{s}$ ) the formation and growth of new crystallization centers slows down significantly and when they reach a certain critical value they stop altogether. In this case no crystalline structure is formed and the material acquires a structure characterized by a disordered arrangement of atoms - an amorphous material. At the same time if the cooling rate is high enough but does not exceed the critical value the material will have an ultrafine disperse structure. In some cases, it is possible to use controlled transition of material from one state to another to obtain required properties. Particularly in our case there is a need to increase the wear resistance of the material.

Having compared the data on crystallite size obtained by theoretical calculations with the experimental size of CSR, we found out that these values are significantly (almost 2 times) different (the size of CSR is larger). Such a difference is caused, in our opinion, by the fact that all the theoretical calculations are true and were conducted for a pure material (iron) whose properties, of course, differ from the real steels. Besides, we should not forget about such an essential fact as ultrasonic vibrations, which should also appreciably influence the microstructure of the obtained coating.

For copper, the lattice parameter also decreases with increasing voltage value and increases with increasing amplitude. In our opinion, this difference is caused by the fact that copper, as a plastic material, is more susceptible to the influence of material deformations on microstructure parameters. During deformation by ultrasonic vibrations microstructure defects formed in iron will be attracted by softer copper inclusions, forcing them to envelope the boundary between matrix and precipitates, distorting the crystal structure. That is, the value of the lattice parameter will depend on the distance between the copper excretions, which will be smaller the greater its concentration in the coating.

It was also found that there is no amorphous phase in the coated layer at the studied modes. At the same time, according to theoretical calculations, the volumetric content of 
the amorphous phase can reach $100 \%$. This fact is apparently caused by the fact that the areas formed in the coating from the transferred material of the copper electrode, besides contributing to dislocation inhibition, act as impurities which presence is known to be an essential factor influencing growth and formation of new crystallization centers and thus reducing the probability of the amorphous phase formation.

In the case of coating with solid alloy electrode the shift of diffraction peaks for carbide practically does not occur (as compared to the initial substance). It may be caused by two factors. Firstly, according to the calculated data for tungsten the cooling rates arising in the coating are not sufficient for the formation of ultradisperse structures. Tungsten carbide has thermophysical characteristics close to those of tungsten, so for the obtained complex carbide, we can also assume the lack of possibility of formation of ultradisperse structures. Secondly, carbide, which has much higher hardness than iron, will repel formed defects and stop dislocations. I.e., dislocation density will decrease, and the size of formed regions will increase. Accordingly, the lattice parameter will not undergo significant changes as compared to the initial substance. For $\alpha$-Fe the lattice parameter tends to decrease with increasing voltage, as well as with increasing amplitude.

Regarding the results obtained by scanning microscopy, it is known that in crystals containing incoherent inclusions, matrix distortions may occur that harden the crystal much more than the formation of, for example, solid solution [1-7]. In such a case, dislocations can slide around or through the inclusions, or be trapped by them. It is also known that thermal excitation can promote the sliding of dislocations or their inhibition, depending on the material of the inclusions. Such inclusions are called Guinier-Preston zones. It is logical to assume that one of the reasons of hardening properties of the coatings obtained by the ELAC method is the presence of such zones of heterogeneity in them, and having submicrocrystalline dimensions, which is visible from the photo on fig. 3 .

The geometric parameters of these zones depend primarily on the material of the base and inclusions. Thus, in the case of $\mathrm{Al}-\mathrm{Cu}$ alloy, the zones have a flat shape with a thickness of several atomic layers. At the same time, when the size factor is small (for example, for Al-Zn) they have a spherical shape.

\section{Conclusions}

Thus, this work shows the prospects of using the ELAC method for production wearresistant nanostructured coatings. The obtained results can be used for the practical implementation of the technology for hardening machine parts and the choice of optimal operating modes of the unit to product nanostructures.

\section{References}

1. B. Movahedi, Nanocrystalline Materials (2020) DOI: 10.5772/intechopen.90255.

2. C. James, M. Li, Mechanical Properties of Nanocrystalline Materials 1st Edition ISBN-10: 9814241970 (2011)

3. M. Wen, K. Dušek, Protective Coatings (2017) DOI : 10.1007/978-3-319-51627-1.

4. K. Kaushik, B.B. Sridhar, D. Paulo, Coatings (2021) DOI : 10.1007/978-3-030-621636.

5. Advances in Thin Films, Nanostructured Materials, and Coatings, Selected Papers from the 2018 International Conference on "Nanomaterials: Applications \& Properties” (2021) DOI: 10.1007/978-981-13-6133-3. 
6. A.E. Hughes, J.M.C. Mol, M.L. Zheludkevich, R.G. Buchheit, Active Protective Coatings (2016) DOI: 10.1007/978-94-017-7540-3.

7. T.D. Thangadurai, N. Manjubaashini, S. Thomas, H.J. Maria, Nanostructured Materials (2020) DOI: 10.1007/978-3-030-26145-0.

8. S.B. Kudryashev, A.A. Zakalyuzhny, Ultrasonic effect on electric spark forming and development in electroacoustic spraying, Advanced Engineering Research 18, 3 (2018) DOI: https://doi.org/10.23947/1992-5980-2018-18-3-306-310.

9. A. Kochetov, E. Fisunova, T. Lavrenova, O. Baryshnikova, Influence of electroacoustic coating of metals on ordering of dislocating structures, MATEC Web of Conferences (2019) DOI: 10.1051/matecconf/201929800100.

10. K.K. Chawla, Composite Materials (2019) DOI: 10.1007/978-0-387-74365-3.

11. R.J. Boulbes, Troubleshooting Finite-Element Modeling with Abaqus (2020) DOI: 10.1007/978-3-030-26740-7

12. A.N. Tikhonov, A.A. Samarskii, Equations of Mathematical Physics, ISBN-10: 0486664228 (2011)

13. J.I. Goldstein, D.E. Newbury, J.R. Michael, N.W.M. Ritchie, J.H.J. Scott, D.C. Joy, Scanning Electron Microscopy and X-Ray Microanalysis (2018) DOI: 10.1007/978-14939-6676-9.

14. A. Ul-Hamid, A Beginners' Guide to Scanning Electron Microscopy, ISBN 978-3-03007498-2. (2018)

15. R.J. Boulbes, Troubleshooting Finite-Element Modeling with Abaqus (2020) DOI: 10.1007/978-3-030-26740-7. 